\title{
Letter \\ The diagnosis and management of pre-invasive breast disease: editor's reply
}

\author{
Sunil R Lakhani
}

The Breakthrough Toby Robins Breast Cancer Research Centre, Institute of Cancer Research, The Royal Marsden Hospital, London, UK

Correspondence: Sunil R Lakhani (e-mail: Sunil.Lakhani@icr.ac.uk)

Published: 12 November 2003

Breast Cancer Res 2004, 6:E4 (DOI 10.1186/bcr741)

(C) 2004 BioMed Central Ltd (Print ISSN 1465-5411; Online ISSN 1465-542X)

The letter from Badve [1] relating to the series on preinvasive breast disease, published in the September and November issues of Breast Cancer Research [2-10], is timely and very welcome. It rightly points out that one should be careful in changing classification systems based on limited knowledge and that perhaps discarding the term atypical ductal hyperplasia at the present time may be premature. I completely agree with him; however, there are a few issues I feel obliged to clarify.

Many of the authors writing in this series (Stuart Schnitt, Hans Peterse, Sunil Lakhani, lan Ellis) are also members of the World Health Organisation panel involved in the "blue book' on classification of breast disease [11]. In this publication, the term atypical ductal hyperplasia has been retained for exactly the reasons stated by Badve, and the panel came to the consensus that at the present time discarding the traditional classification was premature.

The series produced here is not a consensus statement. They are a series of articles that is designed to educate with regards to current thinking, difficulties and problems of classification and evolving concepts as well as highlighting differences in practice. On behalf of the authors I thank Badve for saying that 'the articles are well written', but his criticism that the articles are in places contradictory is misplaced since this was exactly the intention.

Finally, although I completely agree with the view that it may be premature to discard the term atypical ductal hyperplasia, the arguments he uses to justify this relating to loss of heterozygosity analysis are incorrect. It is not true that 'two mutually contradictory conclusions can be drawn from this [loss of heterozygosity analysis in preinvasive disease and normal tissues] data'. It is not simply the presence or absence of loss of heterozygosity that has been used to support the concept of multistep progression. It is the presence/absence of loss of heterozygosity, the chromosomal regions involved, the frequency of alterations, the morphological similarities and transitions observed, and the data from a variety of molecular studies supporting relationships between lesions that have been used to construct a model of tumourigenesis. It is not true that finding loss of heterozygosity in normal tissues invalidates such a model and is therefore 'of no significance'. Badve is correct in stating that molecular data should not be overinterpreted to support changing the current classification systems, but by the same token care should be exercised not to use the data out of context to support an alternative view.

\section{Competing interests}

None declared.

\section{References}

1. Badve S: The diagnosis and management of pre-invasive breast disease: another point of view. Breast Cancer Res 2004, 6:E3.

2. Evans $A$ : The diagnosis and management of pre-invasive breast disease: radiological diagnosis. Breast Cancer Res 2003, 5:250-253.

3. Pinder SE, Ellis IO: The diagnosis and management of preinvasive breast disease: ductal carcinoma in situ (DCIS) and atypical ductal hyperplasia (ADH) - current definitions and classification. Breast Cancer Res 2003, 5:254-257.

4. Simpson PT, Gale T, Fulford LG, Reis-Filho JS, Lakhani SR: The diagnosis and management of pre-invasive breast disease: pathology of atypical lobular hyperplasia and lobular carcinoma in situ. Breast Cancer Res 2003, 5:258-262.

5. Schnitt SJ: The diagnosis and management of pre-invasive breast disease: flat epithelial atypia - classification, pathologic features and clinical significance. Breast Cancer Res 2003, 5:263-268.

6. van de Vijver MJ, Peterse $\mathrm{H}$ : The diagnosis and management of pre-invasive breast disease: pathological diagnosis - problems with existing classifications. Breast Cancer Res 2003, 5: 269-275.

7. Nerurkar A, Osin P: The diagnosis and management of preinvasive breast disease: the role of new diagnostic techniques. Breast Cancer Res 2003, 5:305-308.

8. Purushotham AD: The diagnosis and management of preinvasive breast disease: problems associated with management of pre-invasive lesions. Breast Cancer Res 2003, 5: 309-312.

9. Reis-Filho JS, Lakhani SR: The diagnosis and management of pre-invasive breast disease: genetic alterations in preinvasive lesions. Breast Cancer Res 2003, 5:313-319. 
10. Jeffrey SS, Pollack JR: The diagnosis and management of preinvasive breast disease: the promise of new technologies in understanding pre-invasive lesions. Breast Cancer Res 2003, 5:320-328.

11. World Health Organisation: World Health Organisation Classification of Tumours. Tumours of the Breast and Female Genital Organs. Edited by Tavassoli FA, Devilee P. Lyon, France: IARC Press; 2003.

\section{Correspondence}

Sunil R Lakhani, The Breakthrough Toby Robins Breast Cancer Research Centre, Institute of Cancer Research, Mary-Jean Mitchell Green Building, Chester Beatty Laboratories, Fulham Road, London SW3 6JB, UK. Tel: +44 207153 5525; fax: +44 207153 5533; email: Sunil.Lakhani@icr.ac.uk 